Original Article | Avicenna J Nurs Midwifery Care. 2019; 27(2):89-96

Avicenna Journal of Nursing and Midwifery Care - ISSN 2676-5748

\title{
The Relationship Between Medication Adherence and Coping Skills in Patients With Heart Failure
}

\author{
Naiemeh Seyedfatemi ${ }^{1}$, Elham Zeinali ${ }^{*}$, Mostafa Bahremand ${ }^{3}$, Abbas Mehran $^{4}$, Mehdi Zeinali $^{5}$ \\ 1. Professor, Nursing Care Research Center, Faculty of Nursing \& Midwifery, Iran University of Medical \\ Sciences, Teheran, Iran \\ 2. MSc. in Nursing, Faculty of Nursing \& Midwifery, Iran University of Medical Sciences, Teheran, Iran \\ 3. Associate Professor, Cardiologist, Kermanshah University of Medical Sciences, Kermanshah, Iran \\ 4. Lecturer, Department of Biostatistics, Faculty of Nursing \& Midwifery, Tehran University of Medical \\ Sciences, Teheran, Iran \\ 5. BSc. in Nursing, Faculty of Nursing \& Midwifery, Kermanshah University of Medical Sciences, \\ Kermanshah, Iran
}

\begin{tabular}{lr}
\hline \multicolumn{2}{c}{ Article Info } \\
\hline & \\
Received: & $2018 / 03 / 09$ \\
Accepted: & $2018 / 12 / 30$ \\
Published Online: & $2019 / 05 / 22$
\end{tabular}

DOI: $10.30699 /$ sjhnmf.27.2.89

Original Article

Use your device to scan and read the article online

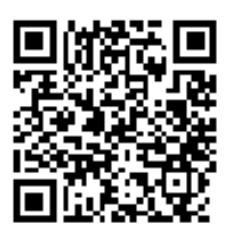

\section{Abstract}

Introduction: Medication adherence is essential to improve outcomes emanated from the disease. The increase in the complexity of the medical regimens causes poor adherence in patients with heart failure; also, the progressive nature of Heart Failure (HF) and its complicated drug regimens are mostly stressful. This study has been conducted on the HF patients at the heart hospital of Kermanshah city with the objective of finding the association between medication adherence and coping skills.

Methods: The present research is a descriptive-correlative study. Research cases include $400 \mathrm{HF}$ patients at Imam Ali hospital of Kermanshah in 2015 who were selected using available sampling method. The self-reported epidemiologic characteristics form of HF patients, Morisky medication adherence Questionnaire (1986) and short form of Carver Questionnaire (COPE, 1997) were utilized for data gathering. SPSS 22 software and statistical test of Pearson correlation and descriptive statistical were used to analyze the data.

Results: The result showed that the majority of the studied cases (\%94) had poor medication adherence. Pearson correlation data analysis revealed direct and weak statistical correlation between medication adherence and coping Skills (religion $P=0.036$, acceptance $P=0.019$, use of emotional support $P=0.02$, use of instrumental support $P=0.001$, hummer $P=0.025$, positive reframing $P<0.001$, self-distraction $P=0.002$ ).

Conclusion: Given the weakness of medication Adherence and relationship between medication adherence and coping Skills in HF patients, the application of educational and intervention programs appears to be substantial.

Keywords: Medication Adherence, Coping Skills, Heart Failure

Copyright (C) 2019, This is an original open-access article distributed under the terms of the Creative Commons Attribution-noncommercial 4.0 International License which permits copy and redistribute of the material just in noncommercial usages with proper citation.

How to Cite This Article:

Seyedfatemi N, Zeinali E, Bahremand M, Mehran A, Zeinali M. The Relationship Between Medication Adherence and Coping Skills in Patients With Heart Failure. Avicenna J Nurs Midwifery Care. 2019; 27(2):89-96 


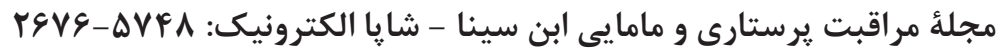

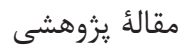

بررسى همبستكى تبعيت دارويى با راهبردهاى مقابلهاى در افراد مبتلا به نارسايى قلبى

نعيمه سيدفاطمى'، الهام زينلى ז"، مصطفى بهرهمند"، عباس مهران"، مهدى زينعلىه

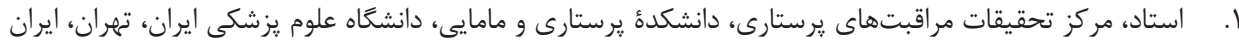

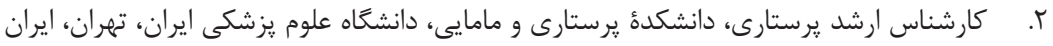

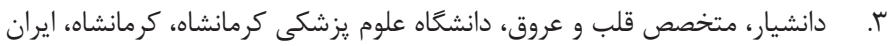

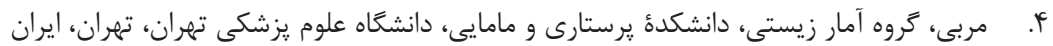

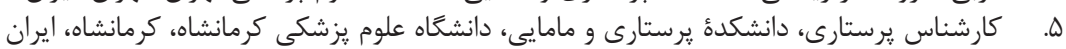

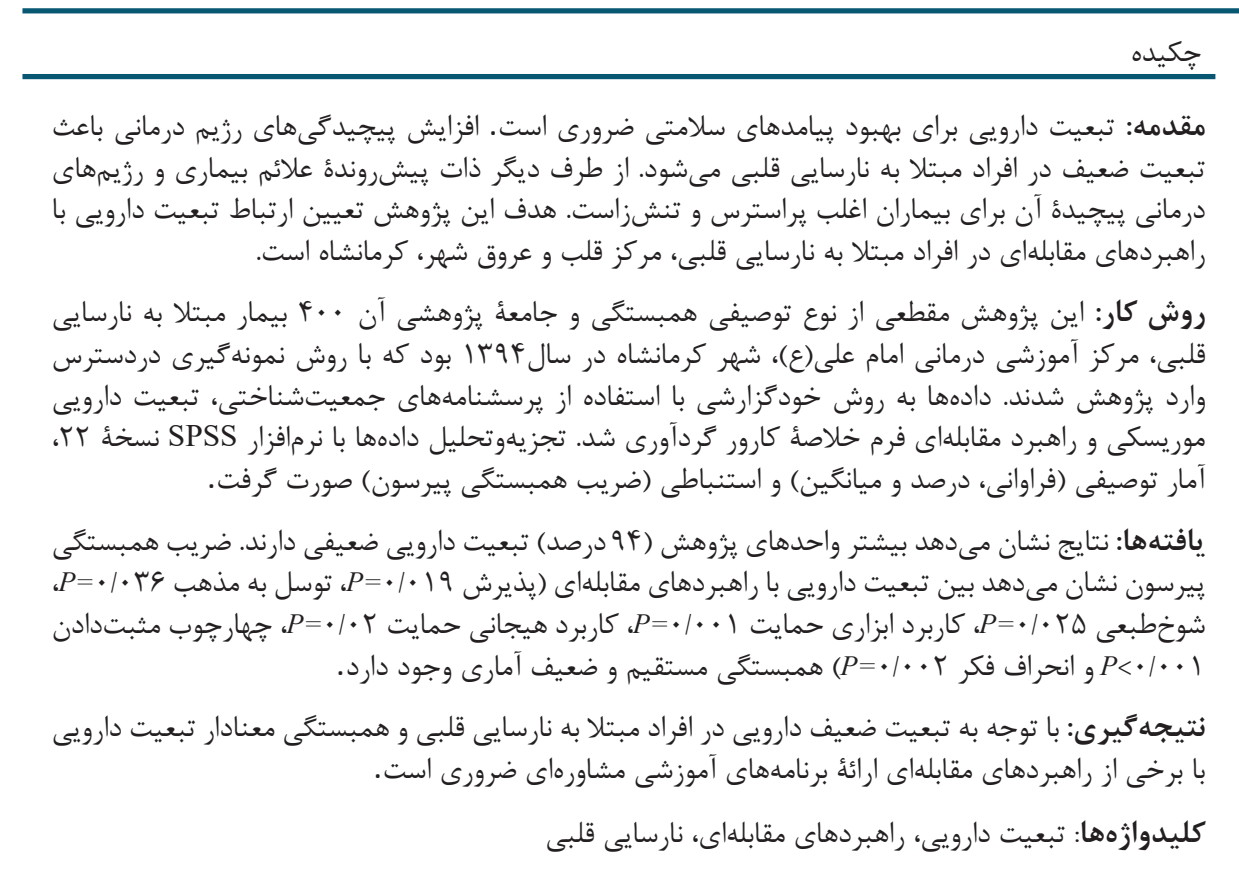

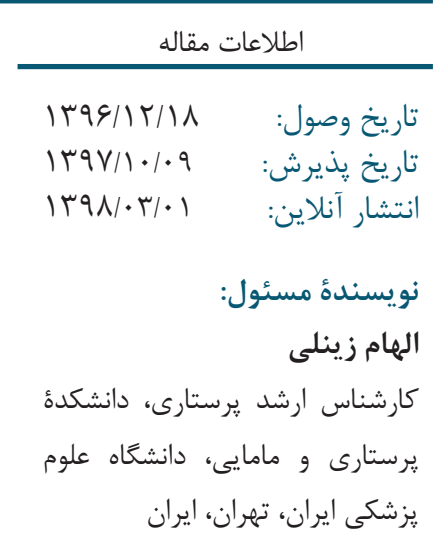

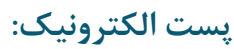
elhamzeinali1984@gmail.com

مقدمه

كه به صورت ميزان مطابقت رفتار افراد با توصيههاى سلامتى

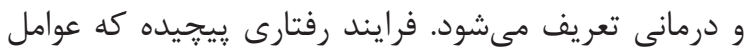

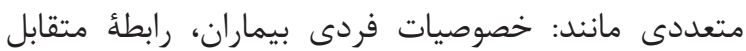

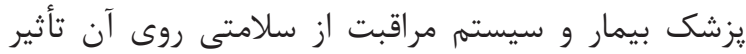

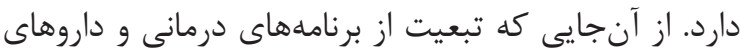

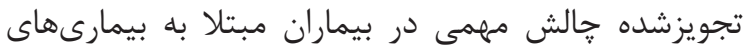

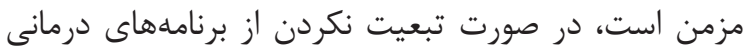

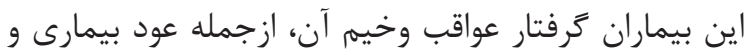

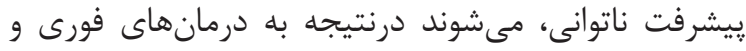

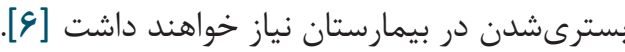

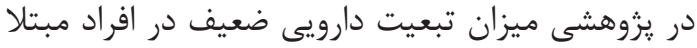

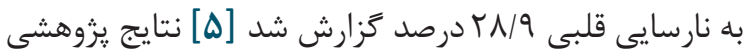

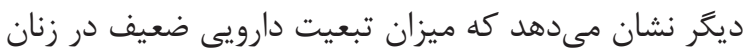

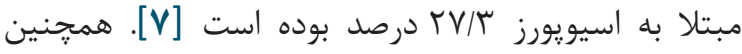

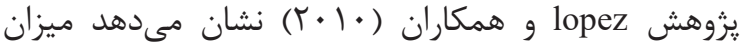

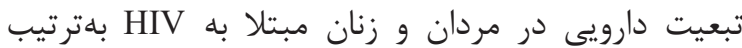

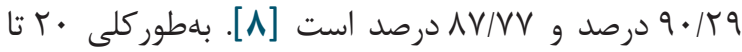

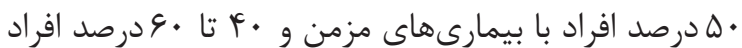

نارسايى قلبى' مرحله نهايى بيمارىهاى قلبى عروقى و بسيار شايع است. اين بيمارى با شيوع بيش از سזميليون نفر

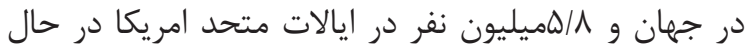

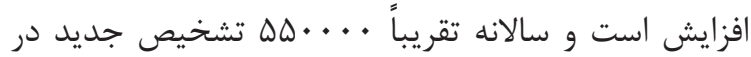
ايالات متحد دارد [1]. ييشآگُهى اين بيمارى ضعيف است به طورى كه سالاانه به مرى حدود ....

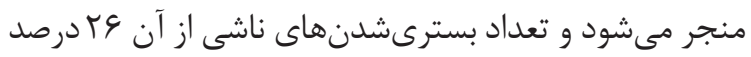
نبيشتر از دهأ حذشته است [ץ]. نارسايى قلبى اولين علت مرگومير در ايران است و بار اجتماعى، اقتصادى و بهداشتى

سنخينى را به جامعه تحميل مى كند [ب].

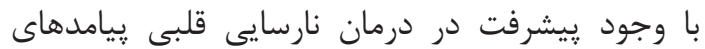

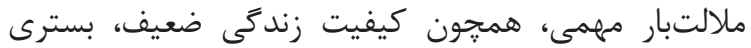

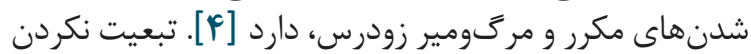

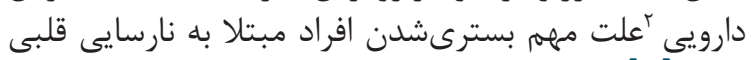

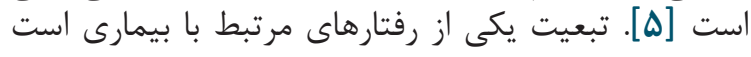

1. Heart Failure (HF)

2. Medication Adherence 
مزمن شناختهشده، بر مبناى ززارش فردى (غيراز ديابت و فشار خون)، وارد يروهش شدند. معيار خروج هم تكميل

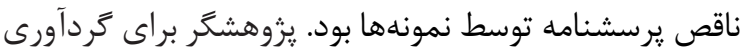

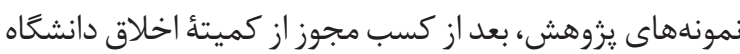
علوم يزشكى ايران با كد (IR. IUMS.1394.9211196205) و اخذ معرفىنامئ لازم براى دانشكاه علوم يزشكى كرمانشاه، به به

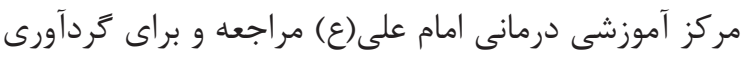

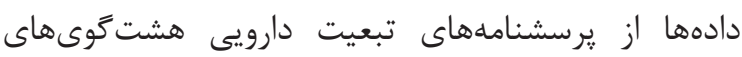
موريسكى و راهبردهاى مقابلهاى فرم خلاصٔ كارور استفاده و مشخصات جمعيتشناختى نمونهاى يزوهشى را به ساير برسشنامها اضافه كرد.

يرسشنامة تبعيت دارويى

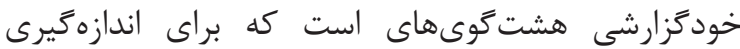

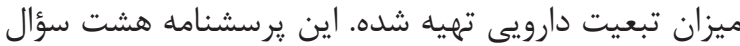

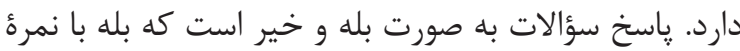

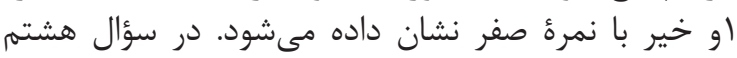

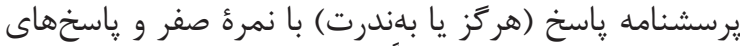

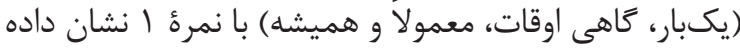

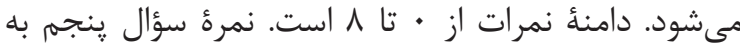

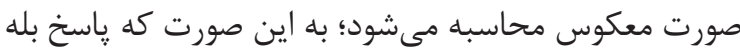

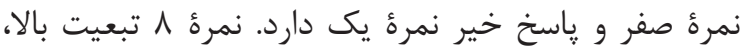

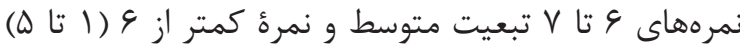

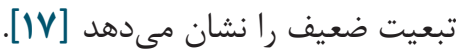

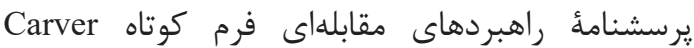

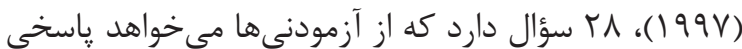

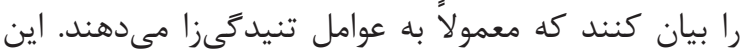

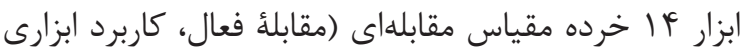

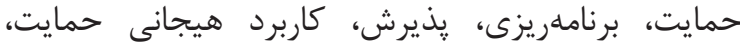

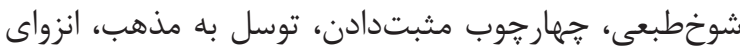

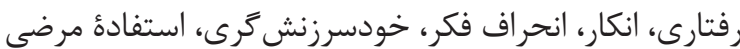

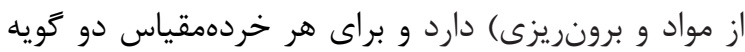

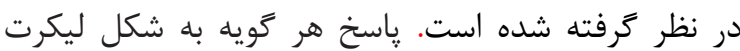

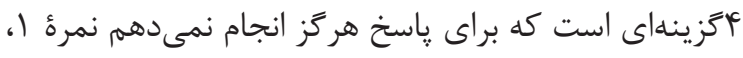

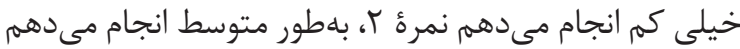

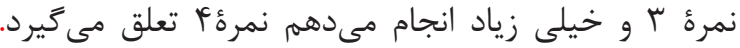

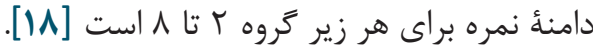

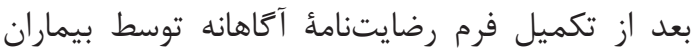

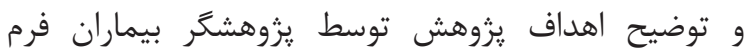

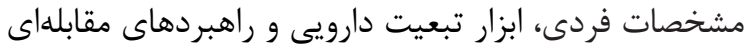

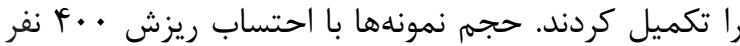

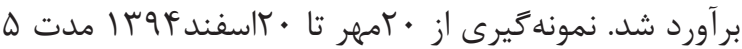

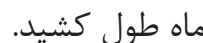

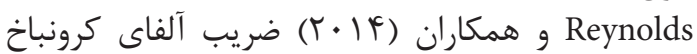

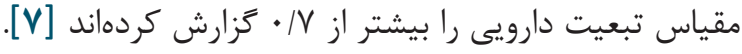

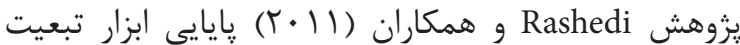

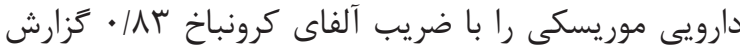

با نارسايى قلبى تبعيت دارويى ندارند [9]. از طرف ديخر

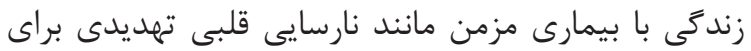

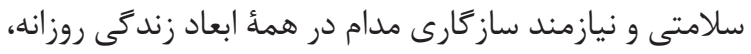

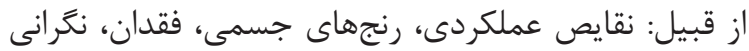

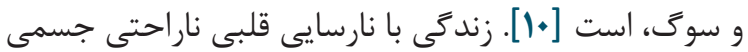

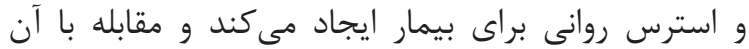

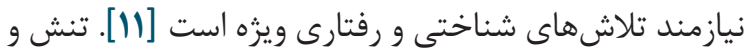

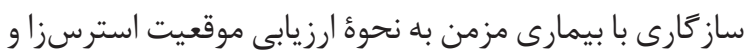

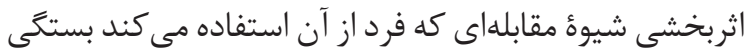

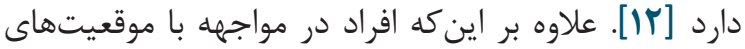

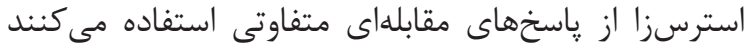

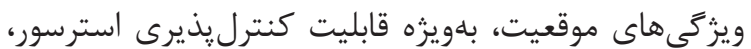

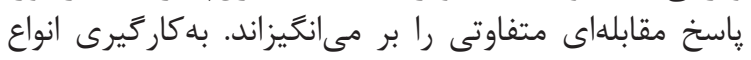

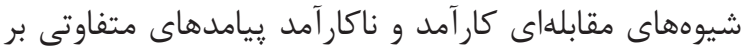

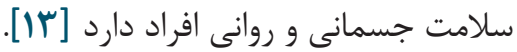

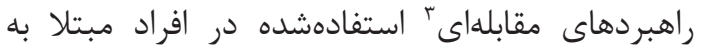

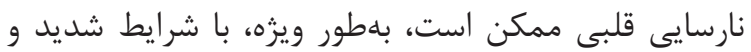

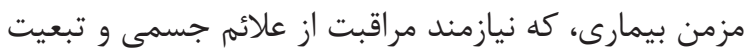

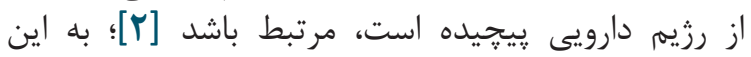

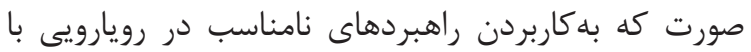

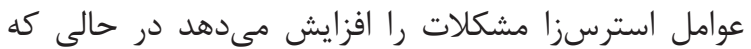

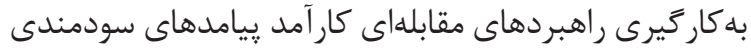

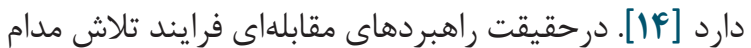

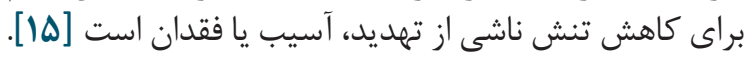

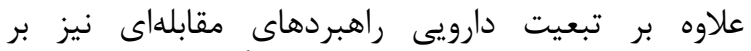

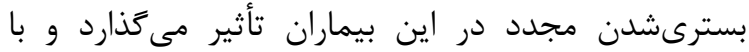

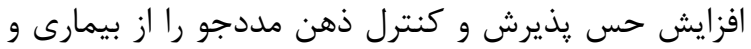

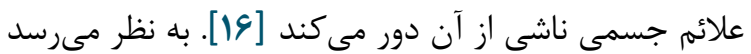

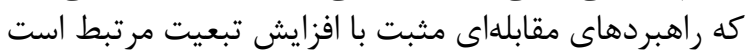

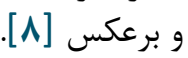
با توجه به اهميت بيمارى نارسايى قلبى و وي بيامدهاى

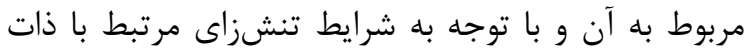

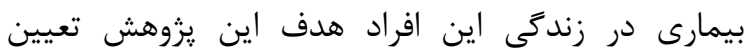

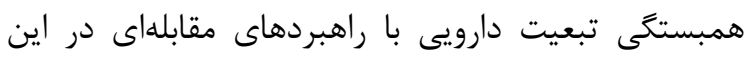

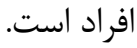

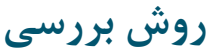

اين يزوهش مقطعى از نوع همبستكى توصيفى است. جامعأ

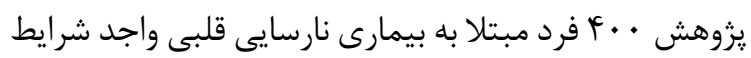

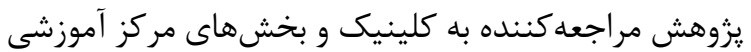
درمانى قلب و عروق امام على (ع)، وابسته به دانشكاه علوم

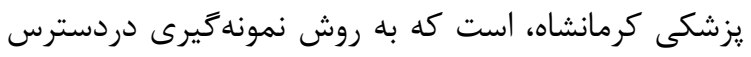
انتخاب شدند. افراد مبتلا به نارسايى قلبى 1 \ تا •وساله كه حداقل سه ماه از تشخيص بيمارىشان كذشته باشد، حداقل سواد خواندن، نوشتن و كسر تخليئ كمتر از • لددرصد داشته باشند و نداشتن همززمان بيمارى هاى نداى جسمى روانى 3. Coping Skills 
بيماران جزء نمونههاى يزوهش قرار نكرفتنند. بعد از وارد كردن

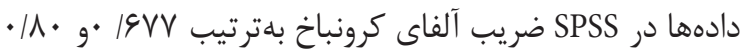

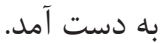

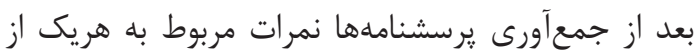

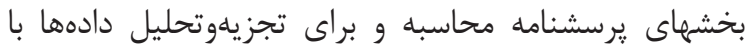

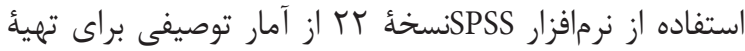

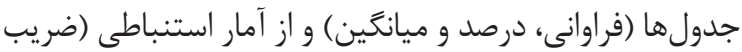
همبستخى پيرسون) استفاده شد.

يافتهها

در مورد مشخصات افراد مبتلا به نارسايى قلبى نتايج نشان

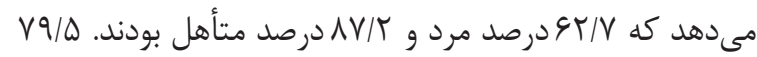
درصد تحصيلات ابتدايى، و9// درصد علت زمينهاى نارسايى

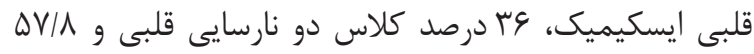
درصد بالاى •D سال داشتند.

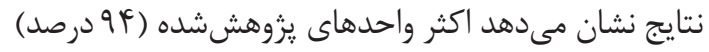

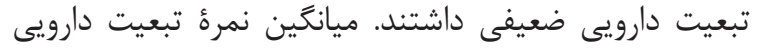

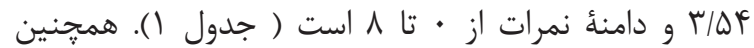

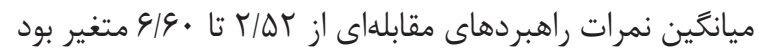

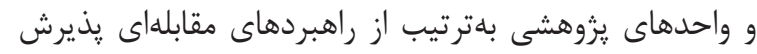

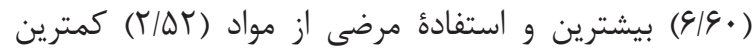

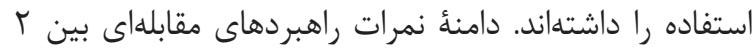

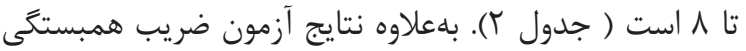

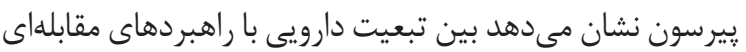

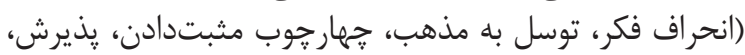

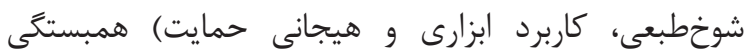
مستقيم و خيلى ضعيف آمارى وجود دارد (جدول بارئ).
كرد [19]. همجنين Ghanei gheshlagh و همكاران (Q| • ( )

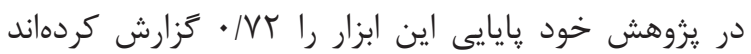

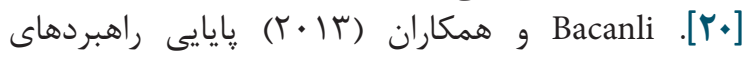

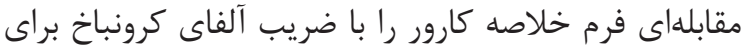

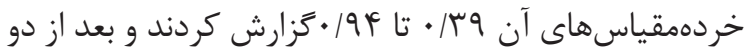

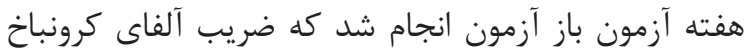

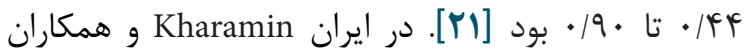

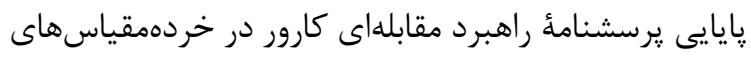

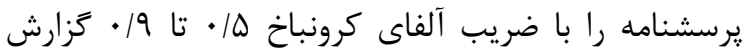

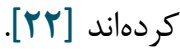

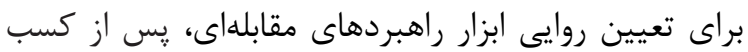

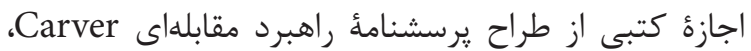

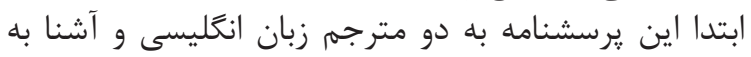

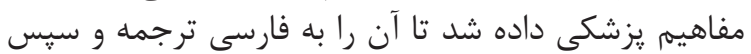

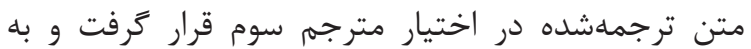

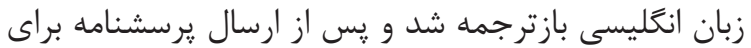

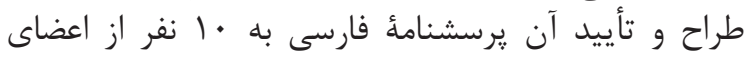

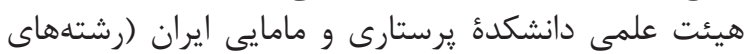

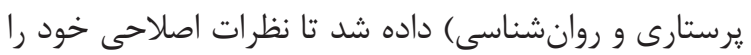

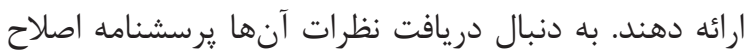

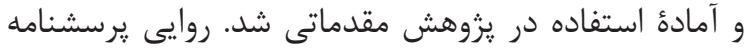

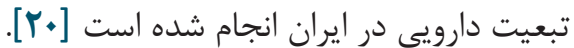

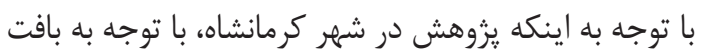

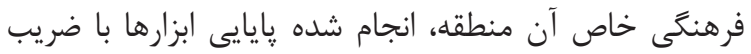

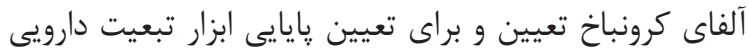

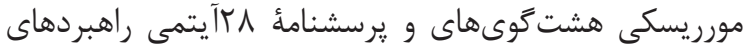

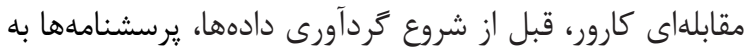

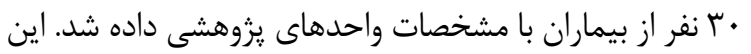

$$
\begin{aligned}
& \text { جدول ا. توزيع فراوانى مطلق و نسبى تبعيت دارويى در افراد مبتلا به نارسايى قلبى } \\
& \text { مركز آموزشى درمانى قلب و عروق امام على (ع) كرمانى }
\end{aligned}
$$

\begin{tabular}{|c|c|c|}
\hline درصد & فراوانى & تبعيت دارويى \\
\hline $1 / 0$ & 4 & تبعيت بالا ( نمرهٔ 凡) \\
\hline$f / \Delta$ & 11 & تبعيت متوسط (نمرءٔ Y-V) \\
\hline 94 & rVG & تبعيت ضعيف ( نمرهٔ كمتر از \&) \\
\hline $1 \cdots$ & f.. & جمع كل \\
\hline \multicolumn{2}{|c|}{$r / \Delta F$} & ميانكَين \\
\hline \multicolumn{2}{|c|}{$1 / V \Delta$} & انحراف معيار \\
\hline
\end{tabular}

جدول r. ميانغين و انحراف معيار زيرمقياسهاى راهبردهاى مقابلهاى در افراد مبتلا به نارسايى قلبى

\begin{tabular}{|c|c|c|}
\hline انحراف معيار & 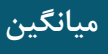 & نوع راهبر دهاى مقابلهاى \\
\hline $1 / F F$ & $\Delta / \uparrow Q$ & 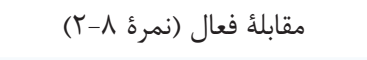 \\
\hline I/VTV & $F / V$ & كاربرد حمايت ابزارى ( نمره 1 -Y) \\
\hline
\end{tabular}

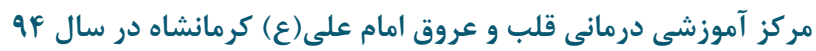




\begin{tabular}{|c|c|c|}
\hline انحر اف معيار & ميانكَين & نوع راهبردهاى مقابلهاى \\
\hline $1 / 4 \mid r$ & $\Delta / r)$ & برنامهريزى ( نمرة 1 - T) \\
\hline $1 / \cdot \wedge \Delta$ & $9 / 9$. & يذيرش ( نمرة م-Y) \\
\hline $1 / 9$. & $\Delta / r q$ & كاربرد حمايت عاطفى ( نمرةٔ 1 - T) \\
\hline T/RT & $\Delta / \cdot \varphi$ & شوخى طبعى (نمرء ^-^) \\
\hline $1 / 091$ & $F / F F$ & 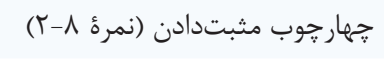 \\
\hline $1 / 495$ & $91 \cdot r$ & توسل به مذهب ( نمرةٔ 1 - Y) \\
\hline l/IVe & $r / \mathcal{k}$. & انزواى رفتارى ( نمرة ^-Y) \\
\hline$|/ \Delta T|$ & $r / 9 F$ & 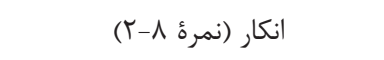 \\
\hline $1 / \pi \wedge V$ & $\varphi / \cdot r$ & انحراف فكر (نمرء ^-؟) \\
\hline$r / T / Q$ & $0 / 19$ & خودسرزنش \\
\hline $1 / 19 V$ & T/QT & استفادهُ مرضى از مواد (نمرة ^-؟) \\
\hline $1 / 4 \cdot 9$ & $\Delta / 11$ & برونريزى (نمرة ^-1) \\
\hline
\end{tabular}

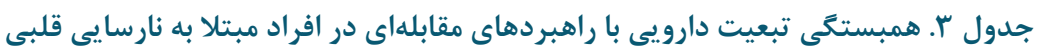

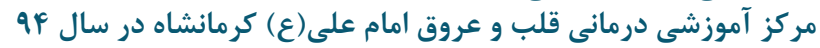

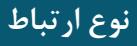
نتيجة آزمون ضريب همبستكَى يبرسون
مستقيم و ضعيف

مستقيم و ضعيف

مستقيم و ضعيف

مستقيم و ضعيف

مستقيم و ضعيف

مستقيهم و ضعيف

$$
r=\bullet / 1 \wedge
$$

$P=\cdot 1 \cdot \cdot 1$

$r=\cdot / 11 \wedge$

$P=\cdot 1 \cdot 19$

$r=\cdot 1119$

$P=\cdot / \cdot r$

$\mathrm{r}=\cdot / 11$

$P=\cdot / \cdot r \omega$

$\mathrm{r}=\cdot / 1 \wedge$

$P<\cdot / \cdot 1$

$r=\cdot / l \cdot \Delta$

$P=\cdot / \cdot r \varphi$

$r=\cdot / \Delta \Delta F$

$P=\cdot \cdot / \cdot r$
راهبردهاى مقابلهاى

كاربرد ابزارى حمايت

يذيرش

كاربرد هيجانى حمايت

شوخطبى

جهار جوب مثبتدادن

توسل به مذهب

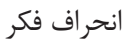

يروهش تبعيت دارويى ضعيفى داشتند. اين يافتهها با نتايج

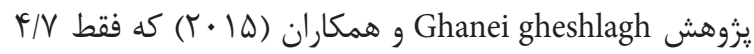
درصد از بيماران ديابتى تبعيت دارويى بالايى داشتند همخوانى فرانى

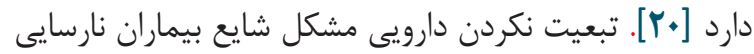

بحث

در اين يزوهش همبستگى تبعيت دارويى با راهبردهاى مقابلهاى

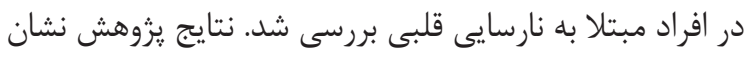

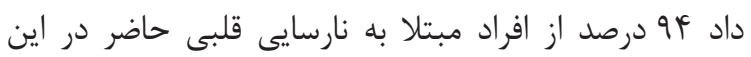




\section{نتيجه}

بلهور كلى اين نتايج نشان مىدهد راهبردهاى مقابلهاى منفى بيشتر در افرادى كه تبعيت دارويى ضعيفى دارند استفاده مىشود و برعكس راهبردهاى مقابلهاى مثبت در افرادى كه

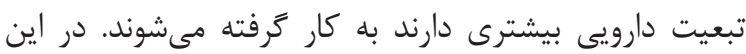
يثوهش تبعيت دارويى با راهبردهاى مقابلهاى (مقابلة فعال،

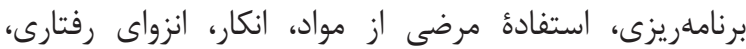
برونريزى و خودسرزنش گرى) همبستخى معنى دار آمارى ندارد. بلهوركلى بين متغيرهاى تبعيت دارويى و و برخى از

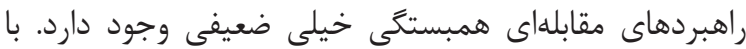

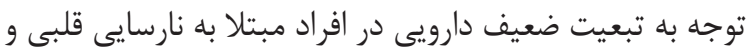

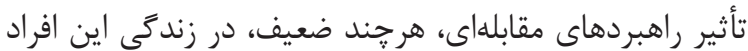

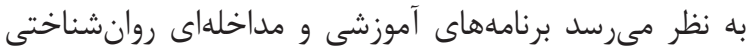

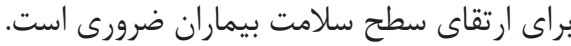

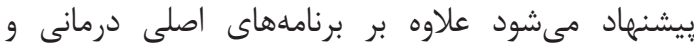

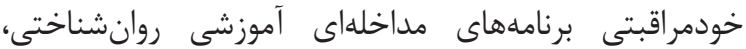

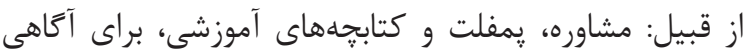

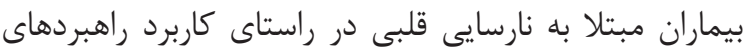

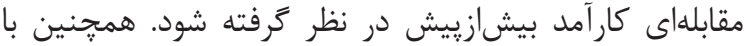

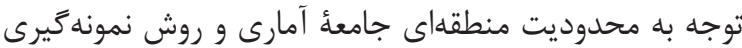

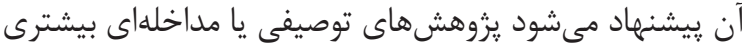

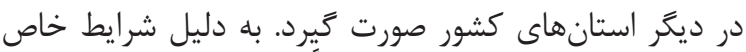
بيماران مبتلا به نارسايى قلبى كاهـاً

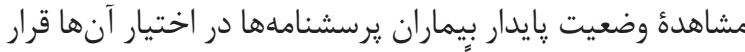

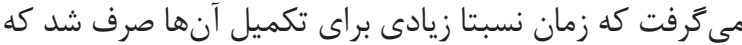

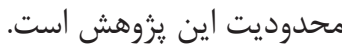
سياسگز ارى

اين مقاله بخشى از نتايج پاياننامه كارشناسى ارشد رشتهٔ روانيرستارى دانشخاه علوم يزشكى ايران است. بدينوسيله يزوهشكَان از مسئولان محترم مركز آموزشى درمانى امام على يلى

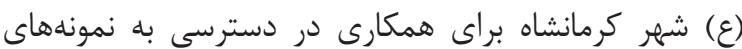
يروهش و از افراد مبتلا به نارسايى قلبى اين مركز آموزشى درمانى كه با تكميل يرسشنامها در دستيابى به اهداف اين يزوهش كمك بسزايى كردهاند تشكر و قدردانى مى كنيم. تعارض در منافع بين نويسندگًان هيجَّونه تعارضى در منافع وجود ندارد.
قلبى است كه روى ييامد درمان اثرات سويى دارد. بنابراين آموزش و تشويق مدام بيماران نارسايى قلبى به تبعيت از رزيم دارويى و گوشزدكردن اثرات سوء تبعيتنكردن دارويى ضرورى

در زمينـُ راهبردهاى مقابلهاى نتايج نشان مىدهد كه

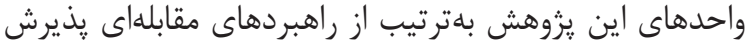

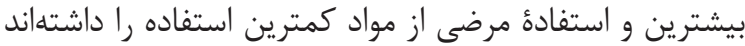

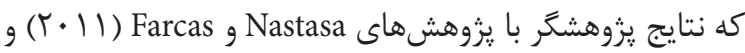
Kasi همبستگى تبعيت دارويى با راهبردهاى مقاى مقابلهاى آزمون

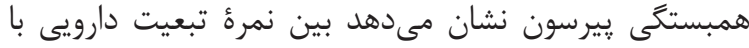

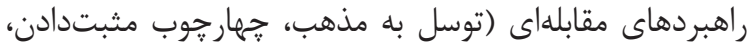

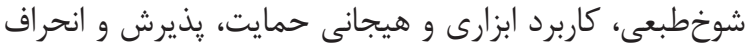

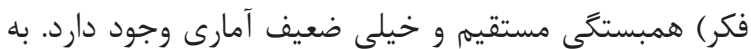

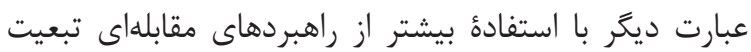

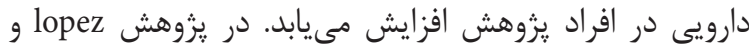

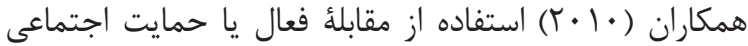

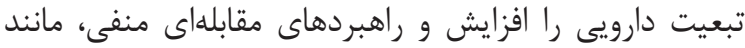

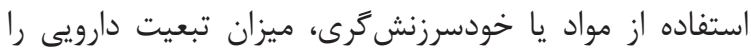

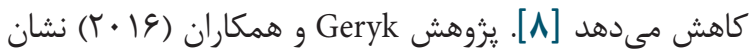

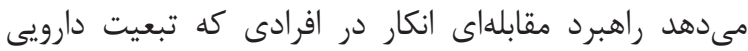

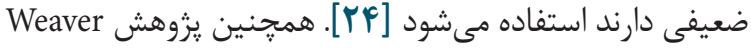

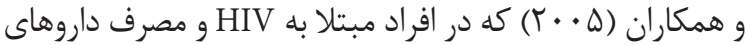

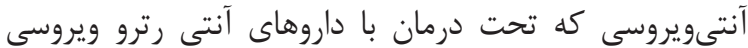

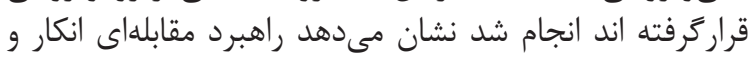

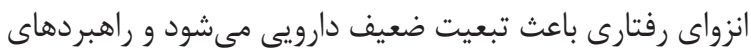

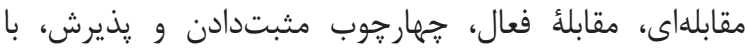

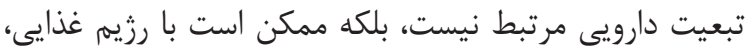

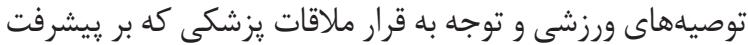

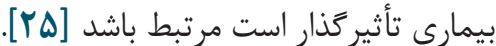

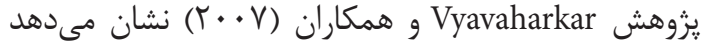

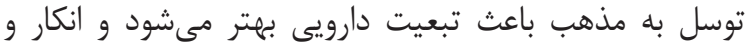

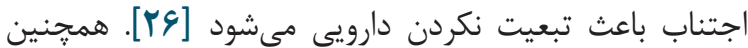

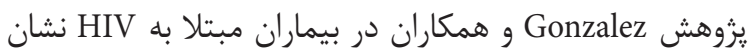

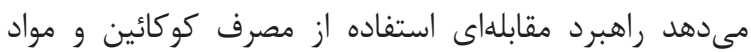

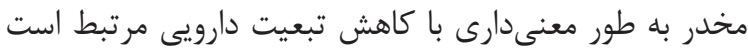

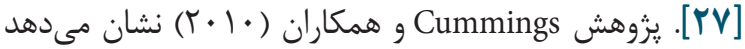

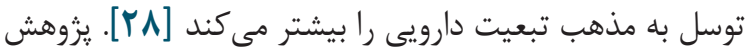
Najimi

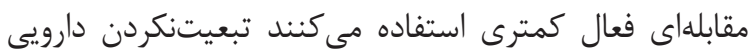

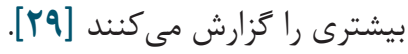

\section{References}

1. Bui AL, Horwich TB, Fonarow GC. Epidemiology and risk profile of heart failure. Nature Reviews Cardiology. 2011; 8(1):30-41.

2. Eisenberg SA, Shen BJ, Schwarz ER, Mallon S. Avoidant coping moderates the association between anxiety and patient-rated physical functioning in heart failure patients. Journal of behavioral medicine. 2012; 35(3):253-261.

3. Seraji M, Tabatabaie P, Rakhshani F, Shahrakipour M. The Effect of Educating Self-Care Behaviors to Patients With Heart Failure in Hospitals of Zahedan. Health Scope. 2013; 2(2):104-109. 
4. Dickson VV, Melkus GDE, Katz S, Levine-Wong A, Dillworth J, Cleland CM, et al. Building skill in heart failure self-care among community dwelling older adults: Results of a pilot study. Patient education and counseling. 2014; 96(2):188-196.

5. Knafl GJ, Riegel B. What puts heart failure patients at risk for poor medication adherence? Patient preference and adherence. 2014; 8:10071018.

6. Masror Roudsari DD, Dabiri G, Parsa yekta Z, Haghani H. Relationship between Adherence to Therapeutic Regimen and Health Related Quality of Life in Hypertensive Patients. Journal of Nursing (IJN). 2013; 26(85):44-54.

7. Reynolds K, Viswanathan HN, Muntner P, Harrison TN, Cheetham TC, Hsu JWY, et al. Validation of the Osteoporosis-Specific Morisky Medication Adherence Scale in long-term users of bisphosphonates. Quality of Life Research. 2014; 23(7):1-12.

8. Lopez EJ, Jones DL, Villar-Loubet OM, Arheart KL, Weiss SM. Violence, coping, and consistent medication adherence in HIV-positive couples. AIDS education and prevention: official publication of the International Society for AIDS Education. 2010; 22(1):61-68.

9. Riegel B, Lee CS, Ratcliffe SJ, De Geest S, Potashnik S, Patey M, et al. Predictors of objectively measured medication nonadherence in adults with heart failure. Circulation: Heart Failure. 2012; 5(4):430-441.

10. Kristofferzon ML, Lindqvist R, Nilsson A. Relationships between coping, coping resources and quality of life in patients with chronic illness: a pilot study. Scandinavian journal of caring sciences. 2011; 25(3):476-483.

11. Farcaş A, Năstasă L. Coping in patients with heart failure. Social Sciences. 2011; 4(53):64-96.

12. Lode K, Bru E, Klevan G, Myhr K, Nyland H, Larsen J. Depressive symptoms and coping in newly diagnosed patients with multiple sclerosis. Multiple Sclerosis. 2009; 15:638-643.

13. Heidari pahlavian A, gharakhani M, mahgoob H. Camparing the amount of experienced stress and coping strategies in CAD patients and healthy individuals .scietific journal of hamedan university of medical science .2010; 3(17): 3338.

14. Mohammadi SD, Torabi SA and Gharaei B. The relationship between coping styles and emotional intelligence in students. Journal of Psychiatry and Clinical Psychology. 2008; 14:176-183.

15. Carels RA, Musher-Eizenman D, Cacciapaglia
H, Pérez-Benítez CI, Christie S, O’Brien W. Psychosocial functioning and physical symptoms in heart failure patients: a within-individual approach. Journal of psychosomatic research. 2004; 56(1):95-101.

16. Carver CS, Connor-Smith J. Personality and coping. Annual review of psychology. 2010; 61:679-704.

17. Morisky DE, Ang A, Krousel-Wood M, Ward HJ. Predictive validity of a medication adherence measure in an outpatient setting. The Journal of Clinical Hypertension. 2008; 10(5):348-454.

18. Carver,CH.S. You Want to Measure Coping But Your Protocol's Too Long: Consider the Brief COPE. Internatinal journal of behavioral medicine. 1997; 4(1):92-100.

19. Rashedi E, Sohrabi Esmrood F, Shams, G. The effectiveness of cognitive behavioral thrapy in preventing the relapse of bipolar disorder. Clinical Psy. \& Personality/Shahed University. 2011; 5:49-64.

20. Ghanei gheshlagh R, ebadi A, Veisi Rayegani AA, Nourozi Tabrizi K, Dalvandi A, Mahmoodi H. Determining Concurrent Validity of the Morisky Medication Adherence Scale in Patients with Type 2 Diabetes. Iranian Jornal of rehabilitation research in nursing. 2015; 1(3):24-30.

21. Bacanli H, Surucu M, Ilhan T. An Investigation of Psychometric Properties of Coping Styles Scale Brief Form: A Study of Validity and Reliability. Educational Sciences: Theory and Practice. 2013; 13(1):90-96

22. Kharamin SH A, Nili H, Mohammadi H, Mobasheri QH. Comparison of coping methods against stress in gastroduodenal ulcer patients, irritable bowel syndrome patients and normal individuals. Journal of armaqan-e-danes. 2008; 87(2).

23. Kasi PM, Naqvi HA, Afghan AK, Khawar T, Khan FH, Khan UZ, et al. Coping styles in patients with anxiety and depression. ISRN psychiatry. 2012; 2012:1-7.

24. Geryk LL, Blalock SJ, DeVellis RF, Jordan JM, Han PK, Carpenter DM. Medication-related Selfmanagement Behaviors among Arthritis Patients: Does Attentional Coping Style Matter. The Open Rheumatology Journal. 2016; 10:60-70.

25. Weaver KE, Llabre MM, Durán RE, Antoni $\mathrm{MH}$, Ironson $\mathrm{G}$, Penedo FJ, et al. A stress and coping model of medication adherence and viral load in HIV-positive men and women on highly active antiretroviral therapy (HAART). Health Psychology. 2005; 24(4):385-392.

26. Vyavaharkar M, Moneyham L, Tavakoli A, 
Phillips KD, Murdaugh C, Jackson K, et al. Social support, coping, and medication adherence among HIV-positive women with depression living in rural areas of the southeastern United States. AIDS patient care and STDs. 2007; 21(9):669-680.

27. Gonzalez A, Mimiaga MJ, Israel J, Bedoya CA, Safren SA. Substance use predictors of poor medication adherence: the role of substance use coping among HIV-infected patients in opioid dependence treatment. AIDS and Behavior. 2013; 17(1):168-173.
28. Cummings JP, Pargament KI. Medicine for the spirit: religious coping in individuals with medical conditions. Religions. 2010; 1(1):28-53.

29. Najimi A, Mostafavi F, Sharifirad G, Golshiri P. Barriers to Adherence to Pharmacotherapy among Patients with Hypertension: A Cross-Sectional Study. International Jornal of Medication Research \& Healteh Sciences. 2016; 5(7S):47-53. 